\title{
Recent patent applications in the area of sequencing
}

\begin{tabular}{|c|c|c|c|c|c|}
\hline Patent \# & Subject & Assignee & Author & $\begin{array}{l}\text { Publication } \\
\text { date }\end{array}$ & Status* \\
\hline WO 9633205 & $\begin{array}{l}\text { Sequencing DNA by parallel oligonucleotide extension. } \\
\text { Involves the extension of initializing oligonucleotide by ligating } \\
\text { probe to form duplex, avoiding electrophoretic separations. }\end{array}$ & $\begin{array}{l}\text { Spectragen } \\
\text { (Chicago, IL) }\end{array}$ & Macevicz SC & $10 / 24 / 96$ & A1 \\
\hline WO 9700967 & $\begin{array}{l}\text { DNA sequencing and labeling using substituted bora- } \\
\text { diaza-indacene fluorophore(s). Labels also useful in } \\
\text { Taqman assays, have narrow bandwidth, show good } \\
\text { photostability, and do not require mobility corrections. }\end{array}$ & $\begin{array}{l}\text { Baylor College of } \\
\text { Medicine } \\
\text { (Houston, TX) }\end{array}$ & $\begin{array}{l}\text { Gibbs RA, } \\
\text { Metzker ML }\end{array}$ & $01 / 09 / 97$ & A1 \\
\hline WO 9627025 & $\begin{array}{l}\text { Large-scale parallel characterization of molecular } \\
\text { recognition by reacting two populations of particles, } \\
\text { detecting labels, identifying particles, optimizing decoupling } \\
\text { and removing labels, and recording presence of labels } \\
\text { not removed. Used for polynucleotide sequencing. }\end{array}$ & Rabani EM & Rabani EM & $06 / 09 / 96$ & A1 \\
\hline WO 9622389 & $\begin{array}{l}\text { DNA polymerase from Thermococcus barossi with } \\
\text { intermediate exonuclease activity and better long-term } \\
\text { stability at high temperature. Useful for DNA sequencing } \\
\text { in PCR, etc. }\end{array}$ & $\begin{array}{l}\text { Pharmacia Biotech } \\
\text { (Piscataway, NJ) }\end{array}$ & $\begin{array}{l}\text { Dhennezel OB, } \\
\text { Jolly JF, Duffaud GD, } \\
\text { Kelly RM, Luhm RA, } \\
\text { Ting EY }\end{array}$ & $07 / 25 / 96$ & $\mathrm{~A} 1$ \\
\hline WO 9639417 & $\begin{array}{l}\text { Methods for performing chemical, biochemical or } \\
\text { biological reactions by trapping particles in an optical } \\
\text { trap and moving them through various reagents in } \\
\text { regions of thin film. Useful for DNA sequencing, etc. }\end{array}$ & Seq & Ulmer KM & $12 / 12 / 96$ & $\mathrm{~A} 1$ \\
\hline US 5571676 & $\begin{array}{l}\text { Identifying genetic alterations by forming mismatched } \\
\text { hybrid, cleavage, and repair to determine sequence } \\
\text { in the gap region. Used to detect disease related } \\
\text { alterations, microbial variants etc., also for positional } \\
\text { cloning of specific genes. }\end{array}$ & Ig Lab & Shuber AP & $05 / 11 / 96$ & A \\
\hline US 5547835 & $\begin{array}{l}\text { Nucleic acid sequencing using mass spectrometry. } \\
\text { Method employs mass spectrometry detectable } \\
\text { modified primers to determine molecular weights } \\
\text { of nucleic acid fragments. }\end{array}$ & $\begin{array}{l}\text { Sequenom } \\
\text { (Boston, MA) }\end{array}$ & Koster H & $08 / 29 / 96$ & A \\
\hline US 5502773 & $\begin{array}{l}\text { Method for processing image data from nucleic acid } \\
\text { sequencer comprising cascade of modules with memory } \\
\text { buffer and neural network processor. }\end{array}$ & $\begin{array}{l}\text { Vanderbilt Univ } \\
\text { (Nashville, TN) }\end{array}$ & $\begin{array}{l}\text { Golden JB, Martin JC, } \\
\text { Tibbetts C, } \\
\text { Torgersen DL }\end{array}$ & $03 / 26 / 96$ & A \\
\hline JP 8509857 & $\begin{array}{l}\text { DNA sequencing by matrix-assisted lase desorption/ } \\
\text { ionization mass spectrometry. Approach uses Sauger } \\
\text { sequencing strategy, assembling information by } \\
\text { analysis of nested fragments obtained by base- } \\
\text { specific chain termination. }\end{array}$ & $\begin{array}{l}\text { Sequenom } \\
\text { (Boston, MA) }\end{array}$ & Koester $\mathrm{H}$ & $10 / 22 / 96$ & w \\
\hline US 5599675 & $\begin{array}{l}\text { Nucleic acid sequencing by stepwise ligation and } \\
\text { cleavage. Procedure eliminates the difficulties } \\
\text { associated with detection and analysis of spatially } \\
\text { overlapping bands of DNA in a gel. }\end{array}$ & $\begin{array}{l}\text { Spectragen } \\
\text { (Chicago, IL) }\end{array}$ & Brenner S & $02 / 04 / 94$ & A \\
\hline WO 9702488 & $\begin{array}{l}\text { Method for DNA sequence and mutation detection. } \\
\text { Approach by normalization of experimental fragment } \\
\text { patterns for nucleic acid polymers subsequently used } \\
\text { for conventional base-calling. }\end{array}$ & $\begin{array}{l}\text { Visible Genetics } \\
\text { (Toronto, Ontario) }\end{array}$ & $\begin{array}{l}\text { Chi V, Dee G, } \\
\text { Gilchrist RD, } \\
\text { Grenn RJ, } \\
\text { Stevens JK }\end{array}$ & $01 / 23 / 97$ & A1 \\
\hline WO 9701646 & $\begin{array}{l}\text { Detection of nucleic acid hybridization by reaction with } \\
\text { transition metal complex by measuring oxidation-reduction } \\
\text { reaction with preselected base. The method exhibits high } \\
\text { structural sensitivity and can resolve single bases. Uses } \\
\text { include DNA profiling and diagnostic assays. }\end{array}$ & $\begin{array}{l}\text { Univ North Carolina } \\
\text { (Chapel Hill, NC) }\end{array}$ & $\begin{array}{l}\text { Johnston DH, } \\
\text { Thorp H }\end{array}$ & $01 / 16 / 97$ & $A_{2}$ \\
\hline
\end{tabular}

Source: Derwent Information, McLean, VA. 'The patents in the table are pending. The status of each application is slightly different from country to country. For further details, contact Derwent scientific and patent information at Derwent North America, 1420 Spring Hill Road, Suite 525, McLean, VA 22102. Tel: 1 (800) DERWENT (info@derwent.com). 